Results: From the 18 women with autoimmune rheumatic disease in follow-up during this period, $2(11.1 \%)$ pregnant women, $2(11.1 \%)$ postpartum women, and $1(5.5 \%)$ post-miscarriage woman developed COVID-19. The mean age was $28 \pm$ 6.3 years, $3(60 \%)$ had systemic lupus erythematosus, $1(20 \%)$ had rheumatoid arthritis, and $1(20 \%)$ had the antiphospholipid syndrome. Clinical features and treatments are shown in Graphic 1 and Table 1. The most frequent symptoms were fever $(80 \%)$, cough $(60 \%)$ and anosmia $(60 \%)$. Four $(80 \%)$ had mild symptoms, and $1(20 \%)$ had severe symptoms requiring intensive care unit admission and mechanical ventilation. Three $(60 \%)$ referred history of contact with a person who had COVID-19. All the patients were using hydroxychloroquine and prednisone. No patient in our study died.

Conclusion: From our population, a total of $27.8 \%$ presented COVID-19. Most of our patients had a mild course of SARS-CoV-2 infection consistent with data from the general population. Additionally, none of our patients had risk factors such as hypertension, diabetes, chronic kidney disease or lung disease. Nonetheless, pregnant women remain a vulnerable population. Prevention measures must continue worldwide to avoid additional COVID-19 morbidity and mortality.

REFERENCES:

[1] Gob.mx. 2021. INFORME SEMANAL DE NOTIFICACIÓN INMEDIATA DE MUERTE MATERNA. [online] Available at: <https://www.gob.mx/cms/uploads/ attachment/file/601780/MM_2020_SE51.pdf> [Accessed 10 January 2021].

[2] Arentz M, Yim E, Klaff L, et al. Characteristics and Outcomes of 21 Critically III Patients With COVID-19 in Washington State. JAMA. 2020;323(16):16121614. doi:10.1001/jama.2020.4326

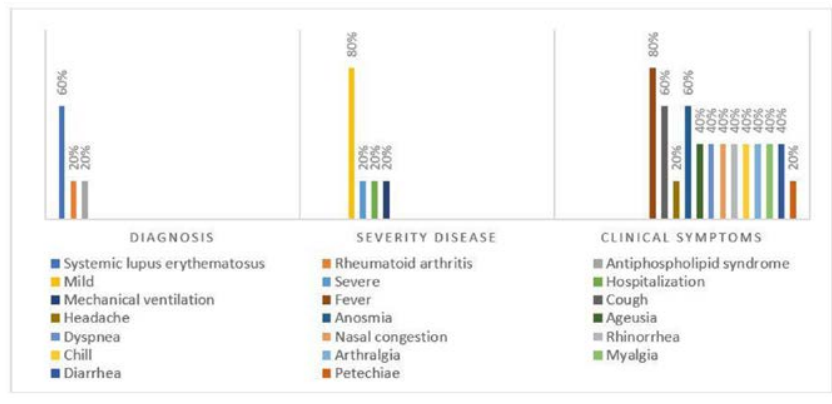

Graphic 1. Diagnosis, severity disease and clinical symptoms of pregnant rheumatic disease patients with COVID-19

Table 1. Features, preventive measures, and treatments of pregnant rheumatic disease patients with COVID-19

\begin{tabular}{lc}
\hline & $\mathrm{N}=5$ \\
\hline Age, years, mean (SD) & $28(6.36)$ \\
Obesity, $\mathbf{n}(\%)$ & $2(40)$ \\
Current occupation, $\mathbf{n}(\%)$ & $3(60)$ \\
$\quad$ Employee & $1(20)$ \\
Student & $1(20)$ \\
Housewife & $5(100)$ \\
Positive PCR test, $\mathbf{n}(\%)$ & \\
Prevention measures, $\mathbf{n}(\%)$ & $2(40)$ \\
Social Distancing & $3(60)$ \\
Quarantine & $3(60)$ \\
$\quad$ Contact with a person who had COVID-19 & \\
Treatments used before disease, $\mathbf{n}(\%)$ & $5(100)$ \\
Prednisone & $5(100)$ \\
Hydroxychloroquine & $2(40)$ \\
Sulfasalazine & $1(20)$ \\
Azathioprine & $1(20)$ \\
Methotrexate* & \\
Rheumatic treatment during disease, $\mathbf{n}(\%)$ & $3(60)$ \\
$\quad$ Continued & $2(40)$ \\
Suspended & \\
\hline
\end{tabular}

PCR: polymerase chain reaction, *Methotrexate was used during conception and suspended immediately after the pregnancy detection.

Disclosure of Interests: None declared

DOI: 10.1136/annrheumdis-2021-eular.2641

\section{POS1221 \\ SARS-COV2 SEROLOGY SCREENING IN SPONDYLOARTHRITIS PATIENTS IN NORTH-EASTERN ITALY: A PILOT STUDY}

A. Ortolan ${ }^{1}$, C. Cosma ${ }^{2}$, M. Lorenzin ${ }^{1}$, G. Cozzi ${ }^{1}$, A. Doria ${ }^{1}$, M. Plebani ${ }^{2}$, R. Ramonda $1 .{ }^{1}$ University of Padova, Rheumatology Unit, Department of Medicine DIMED, Padova, Italy; ${ }^{2}$ University of Padova, Department of Laboratory Medicine, Department of Medicine DIMED, Padova, Italy
Background: Serology could help defining the real extent of Severe Acute Respiratory Syndrome CoronaVirus 2 (SARS-CoV2) diffusion in the population, especially in individuals considered at higher risk of SARS-CoV2 infection (COVID-19), such as Spondiloarthritis (SpA) patients undergoing immunosuppressive therapy or health care workers (HCW). In fact, COVID-19 detection is complicated by the fact that many patients can be asymptomatic. In these cases, it has also been suggested that a weaker immune response might be elicited. In this context, the role of anti-cytokine targeted therapy-commonly used as treatment in SpA- is uncertain, as it is not clear whether it is detrimental or protective towards severe disease forms.

Objectives: The aim of the study was to explore the potential role of serology in detecting previous contact with SARS-CoV2 in SpA patients and HCW, and compare the frequency of positive findings with a control population.

Methods: Consecutive patients affected by axial or peripheral SpA, classified according to Assessment of SpondyloArthritis international Society (ASAS) criteria and undergoing cytokine-targeted therapy, as well as HCW and controls from the pre-COVID-19 era (control group, 2015) were recruited. In SpA patients, disease activity was assessed by Ankylosing Spondylitis Disease Activity Score (ASDAS) and Disease Activity Score on 28-joint-count (DAS28).

Sera from all patients were analysed through chemiluminescent analytical system (CLIA) for the presence of IgG and IgM anti-SARS-CoV2. Patients with a positive serological test (either $\operatorname{lgM}$ or $\lg G$ ) additionally underwent real time Polymerase Chain Reaction (RT-PCR) in nasopharyngeal swabs in order to test for active infection. In SpA patients, serology was repeated after 3 months. Data across the 3 groups were compared by ANOVA or Chi-square, while comparison between 2 groups were conducted by Wilcoxon signed rank test or Chi-Square, for continuous and categorical data respectively. $\mathrm{P} \leq 0.05$ were considered as significant. Results: A total of 396 patients were recruited: $200 \mathrm{SpA}, 95 \mathrm{HCW}$ and 101 healthy controls. SpA patients were mostly (54\%) males, with mean age $49.6 \pm 14.7$ years, and all were treated with anti-TNF $\alpha$ (78\%), anti-IL-17 (9\%) and anti-IL-23 drugs (7\%), or small molecules (6\%). Their disease activity level was moderate-low as assessed by ASDAS (1.95 \pm 0.98$)$ and DAS28 (2.33 \pm 2.02$)$. Among HCW and controls, $35 \%$ and $62 \%$ were male, with mean age $46.7 \pm 12.9$ and $50.6 \pm 10.6$ respectively.

Positive serology (IgM or IgG, or both) was found in $12.5 \%$ SpA patients, $8.4 \%$ $\mathrm{HCW}, 0 \%$ controls $(p=0.001)$. Among these, IgM titres were higher in the SpA group than in $\mathrm{HCW}(2.76 \pm 2.94$ versus $0.80 \pm 0.67 \mathrm{KU} / \mathrm{L}, \mathrm{p}=0.016)$, while $\operatorname{lgG}$ mean titres were lower in the SpA group than in $\mathrm{HCW}(0.88 \pm 3.18 \mathrm{KU} / \mathrm{L}$ versus $1.05 \pm 0.88$ $\mathrm{p}=0.035$ ). SpA patients with positive serology more frequently reported COVID-19 like symptoms than those with negative serology ( $20 \%$ vs $4 \%, p=0.009)$ and 2 had COVID-19 as confirmed by RT-PCR, none with a severe disease course. None of the HCW reported symptoms or tested positive by RT-PCR. In the SpA patients, at 3 months, the mean IgM titre decreased from $2.76 \pm 2.93$ to $2.38 \pm 2.95 \quad(p=0.001)$, while the $\operatorname{lgG}$ titres decreased from $0.89 \pm 3.25$ to $0.31 \pm 0.87(p=n s)$. Interestingly, the IgM or lgG titer at a single-patient level did not seem to change much in terms of absolute value (Figure 1), except in one patient, with documented COVID-19 (positive RT-PCR), in whom IgG level even decreased at 3 months.

Conclusion: Serology revealed that exposure to COVID-19 in SpA patients, as well as $\mathrm{HCW}$, was higher than expected based on reported symptoms. Targeted anti-cytokine therapy could act as a protective factor for a severe disease course in SpA patients. However, in this population, IgG and IgM titres did not change in a clinically significant manner at 3 months, and patient did not seem to develop an immune profile consistent with durable response. This result could be due to a weaker immune response in mild infections, but further studies are warranted to clarify the pathophysiology beyond these observations.
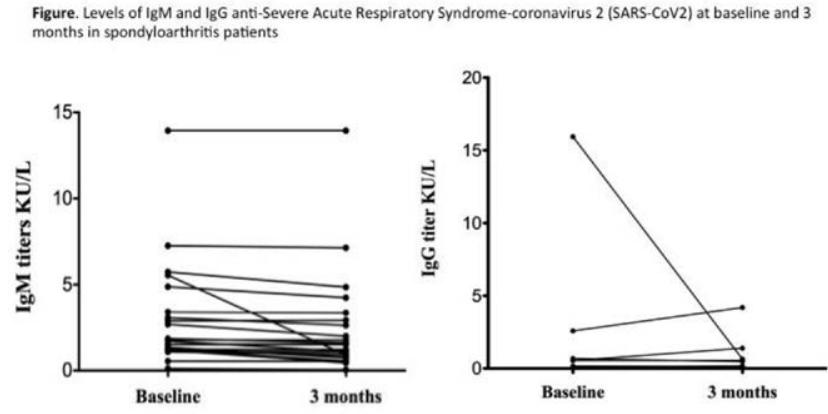

Figure 1.

Disclosure of Interests: Augusta Ortolan: None declared, Chiara Cosma: None declared, Mariagrazia Lorenzin: None declared, Giacomo Cozzi: None declared, Andrea Doria Speakers bureau: Novartis, Abbvie, Pfizer, MSD, Janssen, Glaxosmithkline, Mario Plebani: None declared, Roberta Ramonda Speakers bureau: Novartis, Abbvie, Pfizer, MSD, Janssen DOI: 10.1136/annrheumdis-2021-eular.2681 